\title{
The Relation between Functional Play and Other Forms of Cooperation and Word Learning in ASD
}

\author{
Christina F Papaeliou $^{{ }^{*}}$, Kokonitsa Sakellaki ${ }^{1}$ and Asimenia Papoulidi ${ }^{2}$ \\ ${ }^{1}$ Department of Preschool Education and Educational Planning, University of the Aegean, Greece \\ ${ }^{2}$ Department of Psychology, Panteion University of Social and Political Sciences, Greece
}

*Corresponding author: Christina F Papaeliou, Department of the Preschool Education and Educational Planning, University of the Aegean, Democratias Av. 1, 85-100, Rhodes, Lesbos 81100, Greece, Tel: 22410-99145

\begin{abstract}
This study focuses on the relation between functional play and other aspects of cooperation with language, especially vocabulary production, in children with Autism Spectrum Disorder (ASD). Ten children with ASD (mean CA 54.1 months) were compared with 10 typically developing (TD) children matched for mental and language age (mean CA 17.1 months). Children's behaviors were assessed from video-recordings during spontaneous mother-child play. Results demonstrated that children with ASD take significantly less initiatives for joint attention and spent significantly less time in Elaborated Functional Play. Moreover, Elaborated Functional Play was associated with Expressive Language and word learning in TD children but not in ASD children. Conclusively, it is suggested that in TD children there is an epigenetic relation between preverbal collaboration skills, functional play and language. On the other hand, children with ASD may follow alternative paths to vocabulary development.
\end{abstract}

\section{Keywords}

Autism spectrum disorder, Functional play, Vocabulary production, Theory of intersubjectivity

A significant number of studies in typical and atypical populations has focused on the association between different forms of play, especially functional and symbolic play, and different aspects of language development. Most of these studies follow the Piagetian approach, which suggests that the relation between play and language constitutes an integral part of the development of representational thought, which is egocentric in nature [1-3].

Following the Piagetian perspective, functional play was originally considered as a purely sensorimotor form of activity resulting from repetitive muscle movements with or without objects, for the shake of practicing sensorimotor schemes [4]. According to Piaget [1], functional play is the first of three successive stages preceding constructive and dramatic play. An adequate definition of this form of play was provided by Ungerer \& Sigman [5]: "The appropriate use of an object or the conventional association of two or more objects, such as using a spoon to feed a doll or placing a teacup on a saucer". In this vein, it is suggested that functional play emerges from some form of representation [6], although there is no unanimity about the nature of this representation as well as its relation to symbolic function. Some authors propose a dissociation between functional play and symbolism explaining that unlike functional play, which requires a first order representation e.g. of a pen as a rocket, symbol requires a more complex representational system i.e. a secondorder representation about this representation (a metarepresentation), namely, that the representation is not true [7-9].

Nevertheless, a considerable amount of research does not support the view of dissociation; rather, evidence is provided that at least in typically developing children functional play not only is related to symbolic play and language, but it also facilitates these skills. Focusing on the relationship between functional play and language, Sigman and Ungerer [10] examined preterm and full - term infants in experimental conditions and found that functional play directed towards dolls and other persons as well as meaningfully related sequences of functional acts at $13 \frac{1}{2}$ months were associated with

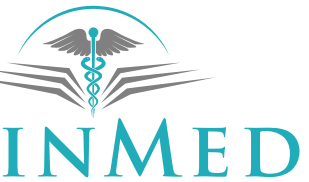

NTERNATIONAL LIBRARY

Citation: Papaeliou CF, Sakellaki K, Papoulidi A (2019) The Relation between Functional Play and Other Forms of Cooperation and Word Learning in ASD. Int Arch Commun Disord 2:012.

Accepted: April 06, 2019; Published: April 08, 2019

Copyright: (C) 2019 Papaeliou CF, et al. This is an open-access article distributed under the terms of the Creative Commons Attribution License, which permits unrestricted use, distribution, and reproduction in any medium, provided the original author and source are credited. 
language measured at $13 \frac{1}{2}$ months and at 22 months. The authors conclude that the consistent relations found between play and language in this research derived from infants' ability to translate experience into symbols that are used as a means of interacting and communicating with others. McCune [11] studied the relation between play and language in a cross-sectional and a longitudinal sample of infants between 8 and 24 months. Data were collected at home, during mother-infant interaction. It was found that the onset of the lexicon was associated with two types of functional play: a) Self-directed functional play (e.g. eating, drinking, sleeping, or grooming), accompanied by sound effects, affect or gestures, revealing an awareness of the pretend aspects of the behavior, and b) Other-directed functional play i.e. having others enact pretend schemes (e.g., feed doll, groom mother). Lewis, et al. [12] administered the Lowe and Costello Symbolic Play Test (SPT) [13] to investigate the relationship between functional play, symbolic play, non-verbal ability, and expressive and receptive language in normally developing children aged between 1 and 6 years. Despite its name, the SPT assesses functional play, rather than symbolic play [14]. When effects of chronological age were partialled out, functional play was correlated significantly with expressive language. Lyytinen, et al. [15] also used the SPT to examine language - play relations in 11018-monthold toddlers and found significant associations of other - directed play with both language comprehension and language production.

The present study aims to contribute to this literature by investigating the relation between functional play and certain aspects of language in children with Autism Spectrum Disorder (henceforth ASD). ASD is a severe neurodevelopmental disorder characterized by impairments in social and communication behaviors, and a restricted range of activities and interests. Once considered rare, ASD is now believed to affect as many as 1 in 60 individuals [16]. ASD affects the manner a developing person moves and responds in the environment - both the physical and the interpersonal. It disturbs the development of interpersonal communication and collaborative action [17].

Earlier studies on the relation between functional play and language in children with ASD has been investigated using mainly two methods i.e. either by comparing ASD children with typically developing children matched for language development, or by directly searching for correlations between functional play and performance on language assessments. In a well-known study BaronCohen [7] compared a group of children with ASD (mean CA 8.1 years) with a group of children with Down Syndrome and a group of typically developing children matched for vocabulary comprehension. Play behavior was assessed in an experimental setting. Results showed that, although children with ASD produced 20 percentage points less functional play compared to typically developing children ( $80 \%$ vs. $100 \%$ ) this difference was not statistically significant, probably because of ceiling effects.

Other studies comparing children with ASD with typically developing children or children with other developmental disorders matched for language development reveal that children with ASD spend less time in functional play in spontaneous situations, but not in structured situations. In structured situations functional acts produced by children with ASD do not differ significantly from those produced by typically developing children or children with other developmental disorders $[10,18,19]$.

However, Jarrold, et al. [20] found that while elicitation increased overall levels of functional play, children with ASD still produced functional acts at a significantly lower rate than language matched learning disabled and normal controls. Other studies also report that functional acts produced by children with ASD are less varied and less integrated compared to those of controls. Ungerer and Sigman [5] divided a group of 16 children with autism aged 3 to 6 years into two groups based on language comprehension. According to their findings, unlike what is the case in typically developing children after 21 months, in children with ASD dolldirected functional play was less than or just equal to that of self-directed functional play. Moreover, doll-directed functional play was more likely to be observed in the high-language group, while children with poor language comprehension spontaneously produced less objectdirected and self-directed functional play than children with better comprehension. Williams, et al. [21] focused on the quality of functional play in ASD children (mean CA 48.8 months) in comparison to children with Down Syndrome and typically developing children matched for expressive and receptive language. Play was assessed in home environment during parent - child interaction. The authors report no significant differences between the three groups in the total amount of functional play. However, it was demonstrated that children with ASD produce less other or doll-directed functional acts than controls.

There are relatively few studies examining directly the relation between functional play and language. Mundy and colleagues [22] investigated social and cognitive correlates of language acquisition in 16 young children with ASD (mean CA 54.5 months) by examining the relations among object play skills, nonverbal communication, and language abilities. Results showed that the total number of different functional play acts was not significantly correlated with the language scores. However, consistent with previous data [5] dolldirected functional play was significantly correlated with receptive language age scores. Certain types of nonverbal communication skills were also shown to be significant correlates of language development in 
this group of autistic children. The play and nonverbal communication variables were not significantly correlated, suggesting that these variables reflect independent psychological factors associated with language development in young autistic children [22].

Sigman and Ruskin [23] examined long-term associations between communication, functional play and symbolic play skills and language in children with ASD (mean MA 25.4 months), in comparison with typically developing children and children with Down Syndrome. According to the findings, functional play did not predict long-term gains when overall language abilities were assessed. Nevertheless, the number of different functional acts predicted gains in expressive language age for children with ASD. Children who engaged in more functional play initially improved more in expressive language skills than children whose functional play was more impoverished initially.

A shift in methods is observed in more recent studies on the relation between functional play and language in children with ASD. Christensen, et al. [24] demonstrated that a group of 18-month-old siblings of older children with autism later diagnosed with ASD performed fewer novel functional play acts than the TD group. Examination of the subtypes of functional play revealed that the ASD sibling group showed fewer selfdirected and other-directed play behaviors than the TD controls. However, the ASD sibling group did not show fewer object directed functional play acts. The authors emphasize that group differences in play are presented without covarying verbal mental age, since deficits in language in children with ASD may act as a proxy for the disorder itself [24]. Also, longitudinal studies examining infants and toddlers high-risk for ASD came to the fore. In the study of Sparaci and colleagues [25] forty-one high-risk infants (HR) with an older sibling with ASD were observed longitudinally at 10, 12, 18 and 24 months of age during a tool use task in a playlike scenario. Changes in grasp types and functional actions produced with a spoon were assessed during elicited tool use. Vocabulary measures were available at 36 months. Three groups were distinguished: Infant siblings later diagnosed with ASD (HR-ASD), infant siblings with language delay and infant siblings with no delay. The results showed that fewer HR-ASD infants produced grasp types facilitating spoon use at 24 months and functional actions at 10 months than HR-no delay. Moreover, production of functional actions in $\mathrm{HR}$ infants at 10 months predicted word comprehension at 12 months and word production at 24 and 36 months.

Other studies which examined associations between functional play and language sum functional and symbolic play together and report results according to the total score, thus providing not an explicit picture about the relation between aspects of functional play and language [26-29].
Taking into account the above considerations, the present study examines the association of functional play and other communicative abilities with language in toddlers with ASD in a naturalistic setting. The hollowing hypotheses were formed:

1. Toddlers with ASD will manifest less joint attention behaviors compared to TD toddlers.

2. Toddlers with ASD will manifest less functional play compared to TD toddlers.

3. Preverbal communicative abilities, joint attention and functional play may be associated with language development, especially word learning, in both groups.

\section{Method}

\section{Participants}

In the present study, participated 10 children with ASD ( 8 boys and 2 girls, mean CA 54.1 months) and 10 typically developing (TD) toddlers ( 8 boys and 2 girls, mean $\mathrm{CA}^{\mathrm{a}} 17.1$ months) who were matched for visuospatial, fine motor, and linguistic abilities on the raw scores of the Müllen Scales of Early Learning (MSEL) (Table 1). Thus, any group differences in nonverbal

Table 1: Visual reception scale, fine motor scale, expressive and receptive language scales, and vocabulary production.

\begin{tabular}{|c|c|c|c|c|}
\hline & ASD & TD & $\mathbf{F}$ & $\mathbf{p}$ \\
\hline \multicolumn{5}{|c|}{ Chronologicalage (months) } \\
\hline mean & 54.1 & 17.1 & 29.1 & $<0.001$ \\
\hline range & $26.2-86.0$ & $9.2-30.1$ & & \\
\hline sd & 19.9 & 5.5 & & \\
\hline \multicolumn{5}{|c|}{ Visual reception } \\
\hline mean & 23.1 & 22.0 & 0.8 & 0.469 \\
\hline range & $14-38$ & $12-36$ & & \\
\hline sd & 5.6 & 6.7 & & \\
\hline \multicolumn{5}{|c|}{ Fine motor } \\
\hline mean & 22.9 & 20.1 & 1.1 & 0.336 \\
\hline range & $14-35$ & $13-38$ & & \\
\hline sd & 5.8 & 5.9 & & \\
\hline \multicolumn{5}{|c|}{ Receptive language } \\
\hline mean & 17.3 & 20.1 & 1.2 & 0.311 \\
\hline range & $6-33$ & $10-33$ & & \\
\hline sd & 6.7 & 7.2 & & \\
\hline \multicolumn{5}{|c|}{ Expressive language } \\
\hline mean & 18.1 & 17.0 & 0.6 & 0.557 \\
\hline range & $8-29$ & $10-29$ & & \\
\hline sd & 7.1 & 5.2 & & \\
\hline \multicolumn{5}{|c|}{ Vocabulary production } \\
\hline mean & 92.2 & 36.7 & 0.9 & 0.389 \\
\hline range & $0-260$ & $0-118$ & & \\
\hline sd & 110.2 & 61.1 & & \\
\hline
\end{tabular}

${ }^{\mathrm{a} C A}$ : Chronological Age. 
communicative and play behaviors may be attributed neither to intelligence nor to language development. All participants were at the one-word stage. In this sample approximately $40 \%$ of children with ASD produced more than 100 words, which is the vocabulary level when children usually begin to produce word combinations [30]. However, none of the participants with ASD could combine words to form simple sentences. Only $18 \%$ of the TD children produced more than 100 words, but none of the produced word combinations either.

Children with ASD were recruited from the Greek Autism Association, a Greek-based parent support group. All participants came from middle-class Greekspeaking families. Mothers' age in the ASD group ranged from $29-44$ years (mean age 37.3 years), while mothers' age in the TD group ranged from 27 - 43 years (mean age 34.6 years). This difference was not statistically significant $(F=2.0, p=0.148, d f=1)$. Most mothers in the ASD group (65\%) had completed high school, while $81 \%$ of mothers in the TD group had received university education. None of the participants exhibited severe sensory or motor deficiencies or had been hospitalized within the previous 6 months. Among children with ASD, 5 attended a public preschool for children with special needs, 4 attended private preschool for children with special needs and 1 child did not attend school. Among TD children only 1 attended private nursery school. Written parental permission was attained before children's participation in the study.

\section{Materials}

The following standardized tests were used in order to assess participants visuospatial, fine motor and linguistic abilities as well as autistic symptoms.

Müllen Scales of Early Learning (MSEL) [31]: The MSEL was used to match the two groups i.e. children with ASD and TD children in visuospatial, motor and language development. This test is administered in infants and preschool children from birth to 68 months and is commonly used in studies of toddlers and young preschoolers with developmental disorders [32]. It consists of 4 scales: Visual Reception scale measures visual processing, visual discrimination, and visual memory. Fine Motor scale measures fine motor planning and control. Receptive Language scale measures understanding of spoken language, knowledge of propositional and spatial concepts, ability to follow oral instructions, auditory short- and long-term memory, auditory organization, sequencing, auditory-visual memory, retrieval of facts, and general knowledge. Failure in the Receptive language scale is often due to an inability to derive linguistic meaning from language. Expressive language scale assesses child's ability to use speech to communicate and express ideas, vocabulary, abstract thinking and reasoning, auditory short- and long-term memory, and comprehension of auditory information.
In some items, it is marked not only whether the child has passed or not, but also the degree of her performance, providing thus a more detailed and accurate account of child's developmental level.

Language Development Survey (LDS) [33]: The LDS is a checklist consisting of 310 words arranged into 14 semantic categories, namely: Food, toys, outdoors, animals, body parts, places, actions, household, personal, people, clothes, vehicles, modifiers, and others. The LDS assesses spontaneous word production in children aged 18 to 35 months. The LDS has good concurrent validity with object and picture naming on various standardized instruments [33-35]. Mothers were asked to mark on the list the words their child says spontaneously, even if they are pronounced in an idiosyncratic way. The form also provides the opportunity for mothers to write in additional words, but these words were not included in statistical analysis.

Child Behaviour Checklist (CBCL) (1.5-5 years) [36]: The $\mathrm{CBCL}$ is a parent-reported measure assessing common maladaptive behaviors in childhood. The Greek version of the $\mathrm{CBCL}$ consists of 100 items grouped in two 'wide-band' factors - internalizing and externalizing behaviors - and seven 'narrow-band' factors, namely emotional problems, anxiety/depression, somatic complaints, withdrawn, sleep problems, attention problems and aggression. Parents are asked to note whether each behavior is 'not true' ( 0 points), 'sometimes true' (1 point) or 'very true' ( 2 points) for their child.

Modified Checklist for Autism in Toddlers (M-CHAT) [37]: The M-CHAT is validated for screening toddlers between 16 and 30 months of age for ASD. The M-CHAT assesses risk for ASD and can be administered and scored as part of a well-child check-up.

\section{Data collection}

All children were visited at their home four times during the month. Home environment was more appropriate for eliciting a representative sample of the child's spontaneous behaviors, compared to the laboratory setting [38]. In the first visit each child was administered the Visual Reception scale and the Fine Motor scale of the MSEL, while the mother completed the LDS as well as a questionnaire on demographic information and the child's medical background. In this questionnaire mothers were also asked to report the age when critical communicative behaviors appeared for the first time; these behaviors included smile (SM), comprehension of questions and orders (CQO), and communicative gestures (CG) such as pointing, showing and offering. In the second visit mothers completed the $\mathrm{CBCL}$ and the M-CHAT and children were administered the Receptive and Expressive Language scales of the MSEL. In the third and fourth visit children were video-recorded while playing with their mother in a semi-structured situation with toys provided by the 
researcher. The set of toys included two different-sized dolls, doll furniture, a tea set, a telephone, a brush and a mirror, a school bus with little people in it, blocks, toy animals, a book, and a wind-up mechanical toy. Mothers were asked to play with their child as they would normally do, introducing all the toys provided. Each play session lasted approximately 30 minutes. This process yielded a total of 1 hour of video-recording for each child.

\section{Coding system}

The coding system for the behavior analysis from the video was intended to have the following characteristics: a) To be concise and not redundant and b) To describe overt behaviors, instead of intentions, of the communicative partners. Particularly complex was the issue of defining functional play, mainly for the following reasons: a) There is no unanimity in the literature for the definition of functional play, and b) This type of play may often be confused with some forms of manipulation as well as pretend play. To study the emergence of functional play in infants, Zelazo \& Kearsley [39] introduced three mutually exclusive categories of play i.e. stereotypical, relational and functional. This study demonstrated a transition from one type of play to the other occurring between 9 - 13 months. The authors operationally defined functional play as the demonstration of adult-like use of objects. However, their important contribution to the definition of functional play was the deliberate exclusion of ambiguous uses, which could not be clearly distinguished from exploratory activities (e.g. mouthing, banging, shaking, rolling). For example, rolling a toy car on the floor could not be distinguished from the simple manipulation of the car. Following this line, only specific behaviors representing unambiguous adult determined functions were defined as functional in the present study. On the other hand, functional play was also differentiated from pretend play based on the three fundamental forms of pretense described by Leslie [9]: Object substitution, attribution of pretend properties, and imaginary objects.

The coding system for the behavior analysis of the present data was based on previous schemes $[40,41]$ and was further expanded from an inductive analysis of the video-recordings. An original coding system was designed which was used by 2 researchers in 10\% of the sample of the video recordings that would be eventually analyzed. Inter - and intra-scorer reliability was calculated using Cohen's kappa for each behavior category. Categories showing inter-rater agreement $<75 \%$ were modified, eliminated or replaced. This process yielded a coding system consisting of 15 behavior categories regarding gaze direction, action on object, action on the other and emotion. The behavior categories were then grouped into broader categories according to the complexity of interaction: Initiates Joint Attention (IJA), Responds to Joint Attention (RJA), Simple Functional Play (SFP), Elaborated Functional Play (EFP) and symbolic play (Table 2). Estimated interrater reliabilities for the final coding system were high, ranging from 0.81 to 0.99 .

Table 2: Behavior categories included in type of interaction.

\section{Initiates Joint Attention (IJA)}

- Alternates gaze: Looks at object - Looks at partner's face/eyes - Looks at same object

- Points: Extends index finger in direction of an object

- Shows: Holds out a toy to partner but does not permit her to take it.

- Offers: Puts a toy into partner's hand spontaneously and permits her to take it.

Responds to Joint Attention (RJA)

- Follows interest: Looks at the direction indicated by partner's pointing, giving, or showing.

- $\quad$ Offers after request: Puts object into partner's hand and permits her to take it, after partner's request.

Simple Functional Play (SFP)

- Conventional acts on a single object accompanied by relevant sounds (e.g. for chewing or car noise).

- Conventional acts on object directed to self (e.g., brushing one's hair)

\section{Elaborated Functional Play (EFP)}

- Conventional acts on object directed to partner (e.g., holding toy telephone to the mother's ear).

- Conventional acts on object directed to doll (e.g., placing a spoon to a doll's mouth)

- Conventional use of two or more objects in combination (e.g., stirring a spoon in a pot).

\section{Symbolic Play (SP)}

- Doll as agent: Plays with a doll as if it could act as an independent agent (e.g., could walk)

- Substitution play: Uses an object as if it was a different object (e.g., substituting a ball for food to feed a doll)

- Imaginary play: Creates objects or people that are not present in the immediate environment (e.g., talking to someone on the phone).

\section{Solitary Play (SOLP)}

- Looks around

- Acts on an object without addressing the partner. 
Approximately 20 minutes of continuous footage from each play session for each child were analyzed. The first and last 5 minutes of each session were not analyzed to avoid adaptation and fatigue effects respectively. Times where play was interrupted by irrelevant stimuli (e.g., bell ringing) or where it was difficult to see clearly what the mother and the child were doing were also excluded from the analysis. Microanalysis consists in noting the onset and offset of each codified behavior. This kind of analysis provides information on the duration of each behavior, the initiator and the responder of the interaction as well as the type of interaction. For the microanalysis of the video recordings the EUDICO Linguistic Annotator was used (ELAN). The ELAN is an annotation tool that allows one to create, edit, visualize and search annotations for video and audio data [42].

Video-recording analysis was also utilized in order to investigate the extent to which naming of an object by an adult, while this object is already the child's focus of attention may facilitate word learning. This question has been extensively studied by Tomasello and his colleagues for pseudo words in experimental conditions with typically developing children (for a review see Tomasello) [43]. However, our research examines further this issue in learning of common words in a naturalistic situation by TD children as well as by children with ASD. The word 'car' was chosen as the target word, because it is commonly addressed to infants and young children. Also, all participants in this sample played with the toy car provided by the researchers. As an index of word learning was used the spontaneous production of the word. The production of the word car was initially measured before the video recordings and after their completion. As regards video-recording microanalysis, the process described below was followed: On the video recordings of each child, researchers located the points on the footage where the mother uttered the word 'car' and defined a framework around the mother's utterance called 'episode'. An 'episode' begins when either the mother or the child first look at the a car and ends when both the mother and the child shift their attention from the car. The mean duration of car episode for the ASD group was 6.9 and for the TD group was 3.6 minutes. This difference was not statistically significant $(F=1.9, p=0.184)$.

\section{Results}

For the statistical analysis the Statistical Package for Social Sciences (SPSS) was used. Group differences were measured with Analysis of Variance (ANOVA), while correlations were measured with the Pearson Correlation Coefficient $(r)$ or Spearman's Rank Correlation Coefficient $(\rho)$ in cases a variable was highly skewed.

\section{Group differences in maternal reports on critical communicative behaviors}

Group comparisons on maternal reports produced significant results revealing that in children with ASD critical communicative behaviors appear for the first time much later compared to TD children. According to maternal reports in children with ASD smile first appeared on average at 4.9 months, while in TD children smile first appeared on average at 2.6 months $(F=4.1, p=0.029$, $\mathrm{df}=1, \eta^{2}=0.224$ ). Moreover, mothers in the ASD group reported that their children first produced communicative gestures on average at 30.7 months, while this ability first appeared in TD children on average at 12.2 months $(F=$ 8.5, $p=0.002, d f=1, \eta^{2}=0.447$ ). Also, mothers reported that children with ASD begin to understand questions and orders on average at 31.3 months, while in the TD group this ability was reported to first appear at 12.3 months $(F=$ $8.2, p=0.002, d f=1, \eta^{2}=0.379$ ).

\section{Group differences in types of interaction and play}

The manifestation of types of interaction and play was calculated per minute. Findings show that children with ASD spent statistically significantly less time in Initiations of Joint Attention ( $F=8.6, p=0.012$, df $\left.=1, \eta^{2}=0.399\right)$. No group differences were observed in Response to Joint Attention ( $F=2.1, p=0.177, d f=$ $1, \eta^{2}=0.136$ ) (Figure 1). Moreover, children with ASD manifest significantly less Elaborated Functional Play $\left(F=4.8, p=0.047, d f=1, \eta^{2}=0.270\right)$,but significantly more Solitary Play $\left(F=9.1, p=0.010, d f=1, \eta^{2}=0.412\right)$. Although TD children spent almost twice as much time in Simple Functional Play compared to children with ASD, this difference was not statistically significant $(F=$ 2.9, $p=0.183, d f=1, \eta^{2}=0.182$ ) (Figure 2).

\section{Correlations between types of interaction and play}

Results of the Pearson $r$ correlation coefficient test showed no significant correlations were between different types of interaction i.e. Initiation for Joint Attention, Response to Joint Attention, Simple Functional Play and Elaborated Functional Play in the

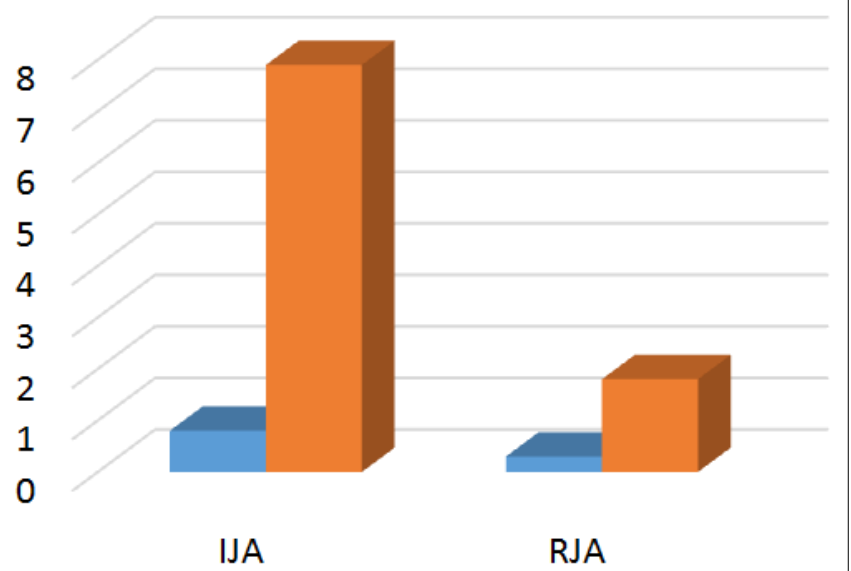

$\square$ ASD $\square$ TD

Figure 1: Group differences in types of interaction. 
TD group. However, in the ASD group Response to Joint Attention was significantly positively correlated with Simple Functional Play and Elaborated Functional Play. Moreover, Elaborated Functional Play was significantly positively correlated with Initiation of Joint Attention (Table 3).

\section{Correlations between maternal reports and types of interaction, play and language}

Pearson correlation showed that in TD children

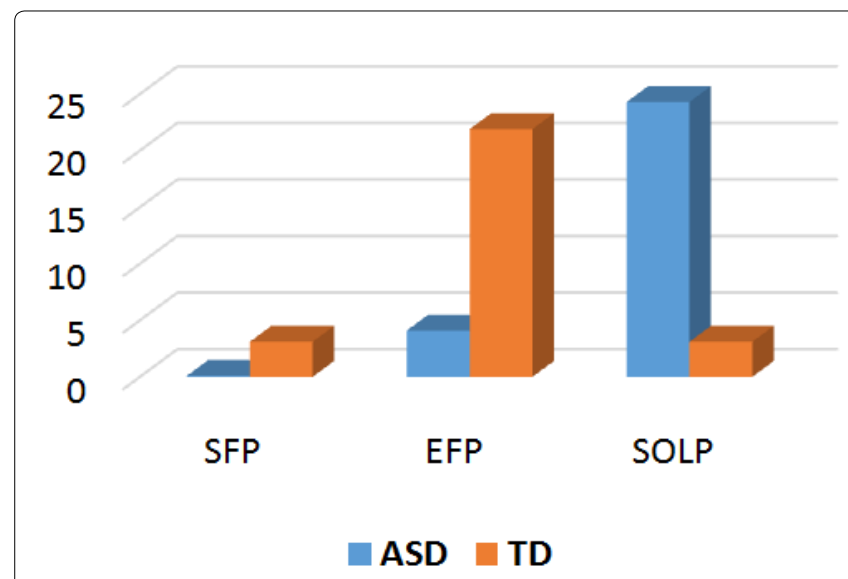

Figure 2: Group differences in types of play.

Table 3: Correlations between types of interaction and play.

\begin{tabular}{|l|l|l|l|l|}
\hline \multicolumn{3}{|c|}{ ASD } & \multicolumn{3}{l|}{ TD } \\
\hline & SFP & EFP & SFP & EFP \\
\hline IJA & 0.525 & $0.618^{*}$ & -0.118 & 0.426 \\
\hline RJA & $0.706^{*}$ & $0.689^{*}$ & -0.441 & -0.378 \\
\hline
\end{tabular}

"p $<0.05 ; " p<0.01 ; " * p<0.001$. there was a significant negative relation between the age of first appearance of Smile, according to maternal reports, and Initiation of Joint Attention. Moreover, there was a significant positive relationship between the first appearance of Communicative Gestures and Initiation of Joint Attention, Elaborated Functional Play, Expressive Language and Vocabulary Size. The first appearance of Comprehension of Questions and Orders also showed significant positive correlation with Simple Functional Play, Elaborated Functional Play, Expressive Language and Vocabulary Size. On the other hand, in the ASD group only the first appearance of Comprehension of Questions and Orders was significantly positively correlated with Initiation of Joint Attention (Table 4).

\section{Correlations between types of interaction and play with language}

Results demonstrated that in the TD group Expressive Language as well as Vocabulary Size were significantly positively correlated with Elaborated Functional Play, while Receptive Language did not correlate significantly with any type of interaction. On the contrary, in the ASD group none of the language variables was significantly correlated with any of the type of interaction (Table 5).

\section{Predictive model}

Knowledge of the word car was measured directly with the MSEL- Language as well as through maternal reports on the LDS. It was demonstrated that before the study 4 out of 10 children with ASD could produce the word car, while this was the case for 1 out of 10 TD children. Measures after the study showed that none of

Table 4: Correlation between maternal reports and types of interaction, play and language.

\begin{tabular}{|c|c|c|c|c|c|c|}
\hline & \multicolumn{3}{|l|}{ ASD } & \multicolumn{3}{|l|}{ TD } \\
\hline & SM & CG & CQO & SM & CG & CQO \\
\hline IJA & 0.146 & 0.213 & $0.975^{\star \star *}$ & $-0.831^{* * *}$ & $0.739^{* *}$ & -0.018 \\
\hline RJA & 0.258 & 0.319 & 0.131 & 0.288 & 0.224 & -0.318 \\
\hline SFP & 0.363 & 0.214 & 0.266 & -0.082 & -0.239 & $0.706^{*}$ \\
\hline EFP & 0.254 & 0.336 & $0.666^{*}$ & -0.463 & $0.908^{* \star *}$ & $0.892^{* * *}$ \\
\hline EL & 0.157 & 0.220 & 0.252 & -0.403 & $0.908^{* \star *}$ & $0.826^{* * *}$ \\
\hline RL & 0.208 & 0.193 & 0.223 & 0.164 & 0.525 & 0.553 \\
\hline VOC & 0.212 & 0.416 & -0.258 & -0.424 & $0.847^{*}$ & $0.963^{* * * x}$ \\
\hline
\end{tabular}

" $p<0.05 ; "$ * $p<0.01 ; * * * 0.001$

Table 5: Correlation between types of interaction and play with language.

\begin{tabular}{|l|l|l|l|l|l|l|}
\hline & \multicolumn{3}{|c|}{ ASD } & \multicolumn{2}{c|}{ TD } \\
\hline & RL & EL & VOC & RL & EL & VOC \\
\hline IJA & 0.201 & 0.336 & 0.302 & 0.083 & 0.479 & 0.424 \\
\hline RJA & -0.442 & -0.574 & 0.382 & 0.256 & -0.145 & -0.329 \\
\hline EFP & -0.091 & 0.037 & 0.504 & -0.545 & -0.226 & -0.248 \\
\hline
\end{tabular}

"p $<0.05 ; "$ * $p<0.01 ; *$ *** $p<0.001$. 
the 6 children with ASD who did not know the word car before the study learned it after the study. On the other hand, 8 out of 9 children who did not know the word car before the study learned it after its completion. Moreover, this change was significantly positively correlated with Elaborated Functional Play $(\rho=0.756$, $\mathrm{p}=0.030)^{\mathrm{b}}$.

\section{Discussion}

The present study focused on the role of different forms of functional play and other communicative behaviors exhibited in a naturalistic situation in language development in toddlers with ASD, compared to typically developing toddlers matched for visual reception, fine motor and language development. All participants were at the one-word stage. Functional play was divided in two categories: Simple Functional Play which was defined as the conventional use of a single object or the conventional use of a single object directed to self and Elaborated Functional Play which was defined as the conventional use of objects directed to others i.e. a partner or a doll, as well as the conventional use of objects in combination. In this study, only actions that reveal an awareness of pretense were considered as functional acts according to Zelazo and Kearsley's [39] suggestion, while these acts were also differentiated from symbolic play as defined by Leslie [9].

The findings revealed that in both the ASD and the TD group the dominant form of functional play was Elaborated Functional Play. However, compared to typically developing children, children with ASD demonstrated approximately five times less conventional acts on objects directed to the partner or to a doll or conventional use of two or more objects in combination. These results agree with relevant studies demonstrating that, compared to typically developing children matched for language development, children with ASD exhibit less time in functional play in spontaneous situations $[7,10,18,21,26]$. Also, this study accords with studies demonstrating that although in structured situations children with ASD may not differ from typically developing children in the amount of functional play, the functional play they produce is of a simpler and more fragmented form $[5,20]$. Despite the fact that here children interacted with their mothers spontaneously, mothers of children with ASD verbally incited their children to functional use of objects, and all incidents of functional play in this group followed such prompts. Conclusively, the present study which took place in a naturalistic situation confirms that children with autistic symptoms exhibit deficits in functional play, especially in its more elaborated forms. In addition, as expected, it was demonstrated that children with ASD very few times take the initiative to establish and maintain a joint attentional focus. However, in this study, neither in the

'Spearman $\rho$ was used in this case because the variable "change" was highly skewed. typically developing group nor in the ASD group any form of functional play was correlated with the current ability to initiate or respond to joint attention, and this finding is in agreement with findings from previous relevant studies [22].

As regards the relation between functional play and language it was shown that in typically developing children at the second year of life more elaborated forms of functional play are significantly positively correlated with aspects of language production and especially vocabulary size. More specifically, it was shown that elaborated functional play, which was spontaneously initiated by the child contributed to word learning. In other words, the more a child was involved in conventional use of objects directed to a doll or the partner, the more possible it was to improve her expressive vocabulary. On the contrary, in children with ASD language development was not correlated to any type of interaction.

The findings on the relation between functional play and language regarding the TD group are in agreement with $[5,11,15]$. On the other hand, the finding that other current communicative behaviors such as initiation of joint attention were not correlated with either functional play or any language variable, may be explained by the fact that joint attention is dominant in younger age i.e. around the end of the first year of life [44]. Nevertheless, around the middle of the second year i.e. the age of the participants in this study, the dominant collaborative behavior is functional play [45]. Indeed, it has been argued that joint attention skills constitute a prerequisite for the development of functional play, symbolic play and language. Around the end of the first year, infants exhibit the uniquely human skill to understand persons as intentional agents. This initial step, which relies on innate motives for intersubjective communication, enables young children to participate in cultural activities, such as using objects in a conventional manner and the creation of symbols [44-46].

However, there is no unanimity among studies on the relation between functional play and language in children with ASD. The present study demonstrated that there is no concurrent relation between either Simple or Elaborated Functional Play and receptive language, expressive language or vocabulary size. On the contrary, [5] found that children with ASD with high language comprehension exhibited more functional play than autistic children with low language comprehension. Nevertheless, in contrast to the present study where mother and child interacted spontaneously in a naturalistic setting, in Ungerer and Sigman's [5] study functional play was produced in a strictly structured setting, where the experimenter gave direct and specific instructions or modelled the required action for the child. 
Thus far, deficits in functional play exhibited by children with ASD as well as its relation to language have mainly been accounted for by cognitive deficits. Piaget [1] hypothesized that the emergence of symbols (i.e. symbolic play and language) relies on the child's ability to differentiate objects from the actions she performs on them. This differentiation is partly achieved when the child can direct her actions towards other persons or representations of animate beings (e.g. dolls) i.e. in elaborated functional play, rather than solely towards herself or objects alone. Thus, deficits in the development of representational skills exhibited by children with ASD may be due to failure to differentiate objects from the actions they perform on them.

Other approaches which consider cognitive deficits as the primary cause of autistic symptoms, provide indirect accounts for the relation between functional play and language in children with ASD. In particular (Harris) [47] proposed that children with ASD are impaired in the three phases of symbolism i.e. decentration - moving from self as agent to other as agent in pretense, decontextualization - moving from using realistic objects in pretense, and integration - combining pretend acts to form sequences. Deficits at the early stages of the development of symbolism are already revealed in functional play since children with ASD experience difficulties in decentration as they do not make the transition from self-directed to other-directed functional acts. This deficit reflects their weakness to shift from external, contextually driven and habitual schemas to flexible, internally generated and planned actions. In turn, this difficulty may be accounted for by deficits in executive functioning [20].

Functional acts are conventional actions on objects that are generated by and learnt from the other members of the social community. However, cognitive approaches to functional play and its relation to language seem to neglect this dimension. Apart from that it has been shown that the Theory of Mind is not correlated to either functional or symbolic play [48]. One of the first attempts to steer towards interpretations which consider the social dimension, supports that children with ASD are not highly motivated to functional play for a variety of reasons including desire for social reinforcement, unconventional reinforcer hierarchies, and low expectancies of success $[49,50]$. Nevertheless, there is no robust evidence in favor of this explanation.

The Theory of Intersubjectivity (Tol) proposed by Colwyn Trevarthen $[45,46,51]$ provides empirical support to the view that shared purposes regarding actions, as these are expressed in conventional use of tools and in pretend play, constitute presuppositions for the development of language, since in language acquisition the learner does not learn from another person, but through and with another person [52,53]. In turn, the ability for shared attention and collaborative action springs from an innate awareness of the subjective states of other persons. During the first year of life this awareness develops and leads to more complex forms of collaboration. In particular, neonates demonstrate clear interest in other's expressions, while 2 month - old infants are sensitive to the reciprocity of emotions and capable of recognizing communicativeness and its absence or appropriateness. At 6 months infants demonstrate a more complex management of affect and they respond to invitations to games. A dramatic change at 9 months leads infants to a more pronounced interest in exploring specific emotional reactions of the communicative partner and relating them to external targets as well as to a recognition of commands and prohibitions. At this age an infant exhibits a new readiness to tune in with the intentions and interests of a partner in joint exploration and use of objects. This ability forms the basis for the creation of meanings, imaginative roles, actions, and "tools" that are arbitrary or symbolic [46]. Data obtained from neuro-anatomical studies also advocate the Theory of Intersubjectivity [53-57]. These studies provide evidence that in typically developing individuals the expression of coherent emotions in coordination with the expressions of other persons is regulated by the Intrinsic Motive Formation (IMF), which involves the brain stem, the basal ganglia, and limbic structures. The IMF is present at birth. The later maturing of neocortical circuits, which regulate conscious activity, emerges in reciprocal, dynamic, and increasing involvement with IMF [53].

In this vein, ASD may be accounted for by deviation in prenatal development affecting the IMF, which causes significant functional deficits in the innate motive for intersubjective communication. In the course of development these deficits are manifested in aspects of joint attention, such as pointing, showing, alternating gaze or following other's gaze as well as in functional play. The lack of motivation for cooperative communication may also explain problems in language development often observed in ASD, since language is based on the natural sociability of infants', which serves to intrinsically motivate cooperative awareness leading to the creation of meanings $[51,58]$. Thus, the Theory of Intersubjectivity may explain the concurrent correlation between early manifestations of joint attention i.e. communicative gestures and the ability to comprehend orders and questions, with later expressions of cooperative communication such as functional play and language development observed in typically developing toddlers. Respectively, the Theory of Intersubjectivity provides an explanation for the lack of these correlations in children with ASD observed in this and previous studies [59-61]. Given that children with ASD in this sample are matched for their language abilities with the control group and despite that show deficits in functional play, which seems to play a crucial role in language development in typical population, one 
may hypothesize that children with ASD may follow alternative routes in language development. However, intervention programs aiming to improve functional play seem to have long-term positive effects in language development [62].

The present study has several notable limitations. One is the restricted sample size which increases the risk of type II errors. Moreover, some behaviors were observed for a very short time in either group weakening thus any group comparison. Also, later studies should apply a more detailed system for the behavior analysis which would further differentiate functional play as prompted by mother's verbal or non-verbal behavior or spontaneous.

Despite these limitations the present findings provide evidence for a continuous relation between joint attention, functional play and language development, which is probably based on innate motives for interpersonal communication and collaboration in typically developing children. This relation is disrupted in children with ASD, a condition characterized by disturbance of the innated motives for communication.

\section{Funding}

This study was funded by General Secretariat for Research and Technology, Hellenic Republic, ARISTEIA PROGRAM, National Technical University of Athens, 68/1211.

\section{Ethical Approval}

All procedures performed in this study were in accordance with the ethical standards of the institutional and national research committee and with the 1964 Helsinki declaration and its later amendments or comparable ethical standards.

\section{Informed Consent}

Informed consent was obtained from all individual participants included in the study.

\section{Author Note}

This research was funded by General Secretariat for Research and Technology, Hellenic Republic, ARISTEIA PROGRAM, NTUA, 68/1211.

\section{References}

1. Piaget J (1962) Play, dreams and imitation in childhood Routledge \& Kegan-Paul, London.

2. Sinclair H (1970) The transition from sensory-motor behavior to symbolic activity. Interchange 1: 119-125.

3. Fein GG, Apfel N (1979) The development of play: Style structure and situations. Genetic Psychology Monographs 99: $231-250$

4. Smilansky $S$ (1968) The effects of sociodramatic play on disadvantaged children: Preschool children. oxford, England.

5. Ungerer JA, Sigman M (1981) Symbolic play and language comprehension in autistic children. $J$ Am Acad Child Psychiatry 20: 318-337.

6. Werner H, Kaplan K (1963) Symbol formation. An organismic developmental approach to language and the expression of thought. New York.

7. Baron Cohen S (1987) Autism and symbolic play. British Journal of Developmental Psychology 5: 139-148.

8. Huttenlocher J, Higgins ET (1978) Issues in the study of symbolic development. In: WA Collins, Minnesota symposia on ch iM psychology. Erlbaum, Hillsdale, New Jersey.

9. Leslie AM (1987) Pretense and representation: The origins of "theory of mind." Psychological Review 94: 412-426.

10. Sigman M, Ungerer J (1984) Cognitive and language skills in autistic, mentally retarded and normal children. Developmental Psychology 20: 293-302.

11. McCune $L$ (1995) A normative study of the representational play at the transition to language. Developmental Psychology 31: 198-206.

12. Lewis V, Boucher J, Lupton L, Watson S (2000) Relationships between symbolic play, functional play, verbal and non-verbal ability in young children. Int $\mathrm{J}$ Lang Commun Disord 35: 117-127.

13. Lowe M, Costello A (1976) Symbolic Play Test (Experimental edition); An asse. NFER Nelson, Windsor.

14. Lewis V, Boucher J, Astell A (1992) The assessment of symbolic play in young children: A prototype test. European Journal of Disorders of Communication 27: 231-245.

15. Lyytinen P, Poikkeus AM, Laakso ML (1997) Language and symbolic play in toddlers. International Journal of Behavioral Development 21: 289-302.

16. Baird G, Charman T, Baron Cohen S, Cox A, Swettenham $J$, et al. (2000) A screening instrument for autism at 18 months of age: A 6-year follow-up study. J Am Acad Child Adolesc Psychiatry 39: 694-702.

17. Trevarthen C, Daniel S (2005) Disorganized rhythm and synchrony: Early signs of autism and Rett syndrome. Brain \& Development 27: S25-S34

18. Libby S, Powell S, Messer D, Jordan R (1998) Spontaneous play in children with autism: A reappraisal. J Autism Dev Disord 28: 487-497.

19. Charman T, Swettenham J, Baron Cohen S, Cox A, Baird G, et al. (1997) Infants with autism: an investigation of empathy, pretend play, joint attention and imitation. Dev Psychol 33: 781-789.

20. Jarrold C, Boucher J, Smith PK (1996) Generativity deficits in pretend play in autism. British Journal of Developmental Psychology 14: 275-300.

21. Williams E, Reddy V, Costall A (2001) Taking a closer look at functional play in children with autism. J Autism Dev Disord 31: 67-77.

22. Mundy P, Sigman M, Ungerer J, Sherman T (1987) Nonverbal communication and play correlates of language development in autistic children. J Autism Dev Disord 17: 349-364.

23. Sigman M, Ruskin E, Arbeile S, Corona R, Dissanayake C, et al. (1999) Continuity and change in the social competence of children with autism, Down Syndrome and developmental delays. Monogr Soc Res Child Dev 64: 1-114.

24. Christensen L, Hutman T, Rozga A, Young GS, Ozonoff $S$, et al. (2010) Play and developmental outcomes in infant 
siblings of children with autism. J Autism Dev Disord 40: 946-957.

25. Sparaci L, Northrup JB, Capirci O, Iverson AM (2018) From using tools to using language in infant siblings of children with autism. J Autism Dev Disord 48: 2319-2334.

26. Charman T, Baron-Cohen S, Swettenham J, Baird G, Drew A, et al. (2003) Predicting language outcome in infants with autism and pervasive developmental disorder. Int $\mathrm{J}$ Lang Commun Disord 38: 265-285.

27. Tamis-LeMonda, Catherine S, Bornstein MH (1994) Specificity in mother-toddler language-play relations across the second year. Developmental Psychology 30: 283-292.

28. Toth K, Munson J, Meltzoff AN, Dawson G (2006) Early predictors of communication development in young children with autism spectrum disorder: Joint Attention, Imitation and Toy Play. J Autism Dev Disord 36: 993-1005.

29. Wilson KP, Carter MW, Wiener HL, DeRamus ML, Bulluck JC, et al. (2017). Object play in infants with autism spectrum disorder: A longitudinal retrospective video analysis. Autism Dev Lang Impair 2: 1-12.

30. Bates E, Goodman JC (2001) On the inseparability of grammar and the lexicon: Evidence from acquisition. In: M Tomasello, E Bates, Language development: The essential readings. Blackwell, Oxford, 34-162.

31. Mullen EM (1995) The Mullen scales of early learning: AGS Edition. American Guidance Service, Circle Pines MN USA.

32. Klein-Tasman B, Merivs CB, Lord C, Phillips KD (2006) Socio-communicative deficits in children with WS Performance on the autism diagnostic observation schedule. Child Neuropsychology 13: 444-467.

33. Rescorla L (1989) The Language Development Survey: A screening tool for delayed language in toddlers. J Speech Hear Disord 54: 587-599.

34. Rescorla L, Alley A (2001) Validation of the Language Development Survey (LDS): A parent report tool for identifying language delay in toddlers. J Speech Lang Hear Res 44: 434-445.

35. Rescorla L, Hadicke-Wiley M, Escarce E (1993) Epidemiological investigation of expressive language delay at age two. First Language 13: 5-22.

36. Achenbach TM, Rescorla LA (2000) Manual for the ASEBA Preschool Forms \& Profiles. Youth \& Families. Research Center for Children, University of Vermont, Burlington, Vermont, USA.

37. Robins DL, Fein D, Barton M (1999) Modified Checklist for Autism in Toddlers. Self-published.

38. Papaeliou C, Minadakis G, Cavouras D (2002) Acoustic patterns of infant vocalizations expressing emotions and communicative functions. J Speech Lang Hear Res 45: 311-317.

39. Zelazo PR, Kearsley RB (1980) The emergence of functional play in infants: Evidence for a major cognitive transition. Journal of Applied Developmental Psychology 1: 95-117.

40. Laing E, Butterworth G, Ansari D, Gsödl M, Longhi E, et al. (2002) Atypical development of language and social communication in toddlers with Williams syndrome. Developmental Science 5: 233-246.

41. Papaeliou C, Trevarthen C (2006) Prelinguistic pitch patterns expressing "communication" and "apprehension." J Child Lang 33: 163-178.

42. Hellwig B (2014) User Guide for ELAN, Linguistic
Annotator, version 4.8.0. The Language Archive, MPI for Psycholinguistics, Nijmegen, The Netherlands.

43. Tomasello M (2001) Perceiving intentions and learning words in the second year of life. In: M Bowerman S Levinson, Language acquisition and conceptual development. Cambridge University Press, Cambridge, UK, 132-158.

44. Tomasello M, Carpenter M, Call J, Behne T, Moll H (2005) Understanding and sharing intentions: The origins of cultural cognition. Behavioral and Brain Sciences 28: 675691.

45. Trevarthen C (1994) Infant semiosis. In: W Nöth, Origins of semiosis, Berlin, Germany: Mouton de Gruyter, 219-252.

46. Trevarthen $C$ (2016) From the intrinsic motive pulse of infant actions, to the life time of cultural meanings. In: B Mölder, V Arstila, P.Øhrstrøm, Philosophy and Psychology of Time, Springer Studies in Brain and Mind. Springer International, Dordrecht, The Netherlands, 225-265.

47. Harris PL (1993) Pretending and planning. In: S BaronCohen, H Tager-Flusberg, D Cohen, F Volkmar, Understanding other minds: Perspectives from autism. Oxford University Press, Oxford, England, 112-137.

48. Charman T, Baron-Cohen S, Swettenham J, Baird G, Cox A, et al. (2000) Testing joint attention, imitation, and play as infancy precursors to language and theory of mind. Cognitive Development 15: 481-498.

49. Harris PL (1989) The autistic child's impaired conception of mental states. Development and Psychopathology 1: 191195.

50. Zigler E, Hodapp RM (1986) The retarded child as a whole person. In: E Zigler, RM Hodapp, Understanding mental retardation. Cambridge University Press, Cambridge.

51. Trevarthen $C$ (1982) The primary motives for cooperative understanding. In: G Butterworth, P Light, Social cognition: Studies of the development of Understanding. Harvester Press, Brighton, 77-109.

52. Tomasello M, Kruger AC, Ratner HH (1993) Cultural learning. Behavioral and Brain Sciences 16: 495-552.

53. Trevarthen C, Aitken KJ (1994) Brain development, infant communication, and empathy disorders: Intrinsic factors in child mental health. Development and Psychopathology 6: 597-633.

54. Bush G, Luu P, Posner MI (2000) Cognitive and emotional influences in anterior cingulate cortex. Trends Cogn Sci 4: 215-222.

55. Cowley SJ (2007) How human infants deal with symbol grounding. In: Tony Belpaeme, Stephen J Cowley, Karl F MacDorman, Interaction Studies: Social Behaviour and Communication in Biological and Artificial Systems. John benjamins publishing company, 83-104.

56. Morris JS, Friston KJ, Buchel C, Frith CD, Young AW, et al. (1998) A neuromodulatory role for the human amygdale in processing emotional facial expressions. Brain 121: 47-57.

57. Trevarthen C, Aitken KJ (2001) Infant intersubjectivity: Research, theory, and clinical applications. J Child Psychol Psychiatry 42: 3-48.

58. Trevarthen C, Hubley P (1978) Secondary intersubjectivity: Confidence, confiding and acts of meaning in the first year. In: A Lock, Action, gesture and symbol: The emergence of language, Academic Press. London, UK, 183-229.

59. Lord C, Pickles A (1996) The relationship between expressive language level and nonverbal social communication in 
autism. Journal of the American Academy of Child and Adolescent Psychiatry 35: 1542-1550.

60. Stone WL, Yoder PJ (2001) Predicting spoken language in children with autistic spectrum disorders. Autism 5: 341-361.

61. Travis L, Sigman M, Ruskin E (2001) Links between social understanding and social behavior in verbally able children with autism. J Autism Dev Disord 31: 119-130.

62. Kasari C, Gulsrud A, Freeman S, Paparella T, Hellemann G (2012) Longitudinal follow-up of children with autism receiving targeted interventions on joint attention and play. J Am Acad Child Adolesc Psychiatry 51: 487-495. 